Research

Open Access

\title{
Correlation between the AKI classification and outcome
}

Marlies Ostermann ${ }^{1}$, Rene Chang ${ }^{2}$ and The Riyadh ICU Program Users Group

\author{
1'Departments of Critical Care and Nephrology, Guy's \& St Thomas' Foundation Hospital, Westminster Bridge Road, London SE1 7EH, UK \\ 2Department of Nephrology \& Transplantation, St George's University Hospital, Blackshaw Road, London SW17 0QT, UK \\ Corresponding author: Marlies Ostermann, marlies@ostermann.freeserve.co.uk
}

Received: 25 Mar 2008 Revisions requested: 29 Apr 2008 Revisions received: 16 Sep 2008 Accepted: 20 Nov 2008 Published: 20 Nov 2008

Critical Care 2008, 12:R144 (doi:10.1186/cc7123)

This article is online at: http://ccforum.com/content/12/6/R144

(C) 2008 Ostermann and Chang; licensee BioMed Central Ltd.

This is an open access article distributed under the terms of the Creative Commons Attribution License (http://creativecommons.org/licenses/by/2.0), which permits unrestricted use, distribution, and reproduction in any medium, provided the original work is properly cited.

\begin{abstract}
Introduction The Acute Kidney Injury Network proposed a new classification for acute kidney injury (AKI) distinguishing between three stages. We applied the criteria to a large intensive care unit (ICU) population and evaluated the impact of $\mathrm{AKI}$ in the context of other risk factors.

Methods Using the Riyadh Intensive Care Program database, we applied the AKI classification to 22,303 adult patients admitted to 22 ICUs in the UK and Germany between 1989 and 1999, who stayed in the ICU for 24 hours or longer and did not have end-stage dialysis dependent renal failure.

Results Of the patients, 7898 (35.4\%) fulfilled the criteria for AKI (19.1\% had AKI I 3.8\% had AKI II and 12.5\% had AKI III). Mortality in the ICU was $10.7 \%$ in patients with no AKI, $20.1 \%$ in AKI I, 25.9\% in AKI II and 49.6\% in AKI III. Multivariate analysis confirmed that AKI III, but not AKI I and AKI II, were independently associated with ICU mortality (odds ratio $(\mathrm{OR})=$ 2.27). Other independent risk factors for ICU mortality were age

$(\mathrm{OR}=1.03)$, sequential organ failure assessment (SOFA) score on admission to the ICU (OR $=1.11$ ), pre-existing end-stage chronic health $(\mathrm{OR}=1.65)$, emergency surgery $(\mathrm{OR}=2.33$ ), mechanical ventilation $(\mathrm{OR}=2.83)$, maximum number of failed organ systems $(O R=2.80)$ and non-surgical admission $(O R=$ 3.57). Cardiac surgery, AKI I and renal replacement therapy were associated with a reduced risk of dying in the ICU. AKI II was not an independent risk factor for ICU mortality. Without renal replacement therapy as a criterion, $21 \%$ of patients classified as AKI III would have been classified as AKI II or AKI I. Renal replacement therapy as a criterion for AKI III may inadvertently diminish the predictive power of the classification.

Conclusions The proposed AKI classification correlated with ICU outcome but only AKI III was an independent risk factor for ICU mortality. The use of renal replacement therapy as a criterion for AKI III may have a confounding effect on the predictive power of the classification system as a whole.
\end{abstract}

\section{Introduction}

There is increasing agreement that universal criteria for acute kidney injury (AKI) are needed to facilitate research and progress in the field of acute renal failure [1-3]. In 2002, the Acute Dialysis Quality Initiative (ADQI) workgroup convened an international interdisciplinary group that ultimately proposed the RIFLE classification for AKI, which distinguished between risk, injury, failure, loss and end-stage kidney disease [2]. These criteria have now been applied to more than 70,000 patients with varying acute problems and chronic comorbidities. All studies showed an increase in mortality with worsening RIFLE class. In a systematic review of 13 studies, Ricci and colleagues concluded that there was a clear correlation between the RIFLE classification and outcome [4]. The pooled estimate of relative risk (RR) for death increased from risk (RR $=2.4)$ to injury $(R R=4.15)$ to failure $(R R=6.37)$ compared with non-AKI.

In 2004, the ADQI group and representatives from three nephrology societies established the Acute Kidney Injury Network (AKIN) [3]. Its intentions are to facilitate international, interdisciplinary and intersocietal collaborations and to ensure progress in the field of $\mathrm{AKI}$, including the development of uniform standards for the definition and classification of AKI. As

ADQI: Acute Dialysis Quality Initiative; AKI: acute kidney injury; AKIN: Acute Kidney Injury Network; APACHE: Acute Physiology and Chronic Health Evaluation; Cl: confidence interval; ESRF: end stage dialysis dependent renal failure; ICU: intensive care unit; OR: odds ratio; ROC: receiver operating characteristics; RIFLE: Risk, Injury, Failure, Loss, End stage classification for acute kidney injury; RR: risk ratio; RRT: renal replacement therapy; SD: standard deviation; SOFA: sequential organ failure assessment. 
part of this process, the RIFLE nomenclature and classification was modified to a staging/classification system differentiating between AKI stage I, II and III. In addition, a 48-hour time window for the diagnosis of $A K I$ was introduced to ensure that the process was acute (Table 1).

Using the AKI classification, Barrantes and colleagues found that $31.5 \%$ of 496 patients in a medical intensive care unit (ICU) met the criteria for AKI. Hospital mortality was significantly higher in patients with AKI than in those without $(45.8 \%$ versus 25.7\%) [5]. Bagshaw and colleagues applied the AKI criteria to 120,123 critically ill patients during the first 24 hours after admission to the ICU and compared them with AKI as defined by the RIFLE classification. They concluded that the AKI criteria did not improve the sensitivity and predictive ability of classifying $\mathrm{AKI}$ in the first 24 hours in the ICU [6].

The aim of our study was to apply the AKI criteria to a large ICU population during the entire stay in the ICU and to evaluate the impact of $\mathrm{AKI}$ in the context of other risk factors.

\section{Materials and methods Study population}

We retrospectively analysed The Riyadh Intensive Care Program database which contains demographic and daily physiological data of 41,972 adult patients admitted to 19 ICUs in the UK and three ICUs in Germany between June 1989 and October 1999. The AKI classification is based on changes in serum creatinine within a 48 hour period, treatment with renal replacement therapy (RRT) or reduction in urine output. Our database does not include any creatinine values pre-admission to the ICU, so we decided to include only patients who had at least two creatinine results taken on different days while in the ICU, that is, we only included patients who stayed in the ICU for 24 hours or more or had treatment with RRT on the first day in the ICU. In addition, we excluded 797 patients with pre-existing dialysis dependent end-stage renal failure (ESRF) and three patients with incomplete data. The remaining 22,303 patients were included in the study.

\section{Data analysis}

The AKI criteria were applied to 22,303 patients. Due to a lack of data on 6- or 12-hourly urine volumes, we only used the creatinine criteria to determine the AKI categories. The creatinine criteria describe changes in renal function without specifying the direction of change. As pointed out by experts in the field (personal communication), these creatinine changes could describe two scenarios: AKI based on a progressive rise in creatinine or AKI based on a high creatinine that subsequently falls to baseline. In order to identify patients with AKI based on rising, as well as falling, creatinine values and to incorporate the 48-hour time window for the diagnosis of AKI, we constructed a computer program that compared each day's creatinine value with subsequent values in the following two days until death or discharge from ICU (i.e. day 1 creatinine would be compared with days 2 and 3 , then day 2 value compared with days 3 and 4, etc). [see Additional data files 1 and 2]. Depending on the change, patients were classified as having no AKI, AKI I, AKI II or AKI III. The most severe degree of AKI was recorded as the final $A K I$ stage.

Acute severity was measured using the Acute Physiology and Chronic Health Evaluation (APACHE) II and Sequential Organ Failure Assessment (SOFA) scoring system [7]. Organ system failures were assessed according to the method proposed by Knaus and colleagues [8], supplemented by a definition for gastrointestinal failure (failure to tolerate enteral nutrition) [9]. The highest number of failed organs (excluding AKI) on any day during the stay in the ICU was recorded as 'maximum number of associated organ failure'. The local ethics committee was not involved and the need for informed consent was

Table 1

Definition and classification/staging system for acute kidney injury (AKI)*.

\begin{tabular}{|c|c|c|}
\hline AKI stage & Creatinine criteria & Urine output criteria \\
\hline AKI stage I & $\begin{array}{l}\text { Increase of serum creatinine by } \\
\geq 0.3 \mathrm{mg} / \mathrm{dl}(\geq 26.4 \mu \mathrm{mol} / \mathrm{L}) \\
\text { or } \\
\text { increase to } \geq 150 \%-200 \% \text { from baseline }\end{array}$ & Urine output $<0.5 \mathrm{ml} / \mathrm{kg} /$ hour for $>6$ hours \\
\hline AKI stage II & $\begin{array}{l}\text { Increase of serum creatinine to } \\
>200 \%-300 \% \text { from baseline }\end{array}$ & Urine output $<0.5 \mathrm{ml} / \mathrm{kg} /$ hour for $>12$ hours \\
\hline AKI stage III & $\begin{array}{l}\text { Increase of serum creatinine to } \\
>300 \% \text { from baseline } \\
\text { or } \\
\text { serum creatinine } \geq 4.0 \mathrm{mg} / \mathrm{dl} \\
(\geq 354 \mu \mathrm{mol} / \mathrm{L} \text { ) after a rise of at least } 44 \mu \mathrm{mol} / \mathrm{L} \\
\text { or } \\
\text { treatment with renal replacement therapy }\end{array}$ & $\begin{array}{l}\text { Urine output }<0.3 \mathrm{ml} / \mathrm{kg} / \text { hour for }>24 \text { hours } \\
\text { or } \\
\text { anuria for } 12 \text { hours }\end{array}$ \\
\hline
\end{tabular}

Diagnostic criteria for $\mathrm{AKI}$ includes an abrupt (within 48 hours) reduction in kidney function defined as an absolute increase in serum creatinine of either $0.3 \mathrm{mg} / \mathrm{dl}$ or more $(\geq 26.4 \mu \mathrm{mol} / \mathrm{L})$ or a percentage increase of $50 \%$ or more ( 1.5 fold from baseline) or a reduction in urine output.

*according to Mehta and colleagues [3] 
waived because the study required neither an intervention nor breach of privacy or anonymity.

\section{Statistical analysis}

The statistical package SPSS (Version 14.0, Woking, UK) was used for all statistical analyses. Continuous variables were expressed as mean \pm standard deviations (SD) and $95 \%$ confidence intervals $(\mathrm{Cl})$ or median and range. Student's ttests, chi-square tests, Fisher's exact tests and Mann-Whitney tests were employed in univariate analyses to evaluate statistical significance $(p<0.05)$. Multivariate logistic regression analysis was conducted to identify independent predictors of all-cause ICU mortality and to obtain odds ratios (ORs). Variables that were found to be significant risk factors in univariate analyses $(p<0.05)$ were entered simultaneously in the multivariable model (enter method). These variables included 10 categorical variables (gender, presence of pre-existing endstage chronic illness, mechanical ventilation, AKI categories, RRT, emergency surgery, elective surgery, non-surgical admission, haemoglobin $(\mathrm{Hb})<9 \mathrm{~g} / \mathrm{dl}$ on admission to the ICU and admission after cardiac surgery) and three numerical variables (age, SOFA score and maximum number of associated organ failure). ORs were estimated from the b coefficients obtained, with respective $95 \%$ Cls. Calibration of the model was assessed using the Hosmer-Lemeshow goodness-of-fit test. Discrimination capability was evaluated by determination of the area under the receiver operating characteristics (ROC) curve.

\section{Results \\ Incidence of $\mathbf{A K I}$ and outcome}

Among all 22,303 patients, 7898 (35.4\%) fulfilled the criteria for AKI (Table 2). Of those, 19.1\% had AKI I, 3.8\% fulfilled criteria for AKI II and 12.5\% had AKI III. According to the AKI classification, 14,405 patients $(65.6 \%)$ had no evidence of AKI. In general, AKI III occurred later after admission to the ICU compared with AKI I. On the day when the criteria for maximum AKI stage were fulfilled, $24 \%$ of patients with AKI III had failure of three or more other organs compared with $6.4 \%$ of patients with $\mathrm{AKI}$ II and $3.4 \%$ of patients with maximum AKI I. Similarly, $79.9 \%$ of patients with AKI III were ventilated on the day when they fulfilled the criteria for AKI III compared with $67.4 \%$ of patients with $\mathrm{AKI}$ II and $69.4 \%$ of patients with maximum $\mathrm{AKI}$ I.

Any degree of AKI was associated with a significantly increased all-cause ICU and hospital mortality compared with not having AKI (Table 2). Without controlling for any other risk factors, the OR for death in the ICU was 2.59 for patients with AKI I, 3.24 for patients with AKI II and 9.38 for patients with AKI III compared with not having AKI ( $<<0.0001)$. There was no significant change in outcome in the different AKI stages over time (Figure 1). The AKI classification correlated with length of ICU admission: median length of stay was shortest among patients without $\mathrm{AKI}$ and rose with increasing severity of AKI (Table 2).

\section{Impact of confounding factors}

Patients with AKI had a higher APACHE II score, SOFA score and more failed organ systems on admission to the ICU when compared with patients without AKI (Table 2). In all AKI categories, ICU mortality rose with increasing number of other failed organ systems (Figure 2). In patients with the same maximum number of failed organs, outcome was worst in patients with AKI III. There was no significant difference between AKI I and AKI II patients with the same number of associated failed organ systems. The proportion of patients who needed mechanical ventilation during their stay in the ICU increased from $58.2 \%$ among patients without $A K I$ to $80.8 \%$ in patients with $\mathrm{AKI} I$ and $81.2 \%$ in patients with $\mathrm{AKI}$ II to $86.8 \%$ among patients with AKI III (Table 2).

Among the group of patients with AKI III, 1847 patients $(64.3 \%)$ received RRT (Tables 3 and 4 ) of whom 1728 patients $(93.6 \%)$ were treated with continuous arterio-venous haemofiltration or continuous veno-venous haemo(dia)filtration alone or in combination with intermittent haemodialysis or peritoneal dialysis. The remaining patients had intermittent haemodialysis alone or in combination with peritoneal dialysis. In a univariate analysis, both, ICU and hospital outcome were worse in patients treated with RRT compared with patients with AKI III who did not have RRT (ICU mortality $54.1 \%$ versus 40.6\%; hospital mortality $61.6 \%$ versus $50.5 \%$ ) (Table 3 ). However, patients treated with RRT were generally sicker, as evidenced by a higher APACHE II score and SOFA score on admission to ICU, more associated organ failure and a higher proportion on mechanical ventilation.

\section{Multivariate analysis}

In a multivariate analysis, non-surgical admission, mechanical ventilation, maximum number of associated organ failure, admission after emergency surgery and AKI III were the strongest independent risk factors for ICU mortality, followed by pre-existing end-stage chronic illness, SOFA score on admission to ICU and age (Table 5). In contrast, male gender, $\mathrm{AKI} I \mathrm{I}$ and $\mathrm{Hb}<9 \mathrm{~g} / \mathrm{dL}$ on admission to ICU were not independently associated with ICU mortality. Admission after cardiac surgery, AKI I and RRT were associated with a reduced risk of mortality in the ICU. The area under the ROC curve was 0.88 (Hosmer-Lemeshow chi-square $=106.478$; eight degrees of freedom, $p<0.0001)$.

\section{Additional factors}

Timing and progression of AKI

There was a significantly higher ICU mortality in patients in whom the diagnosis of AKI was based on a rising creatinine level compared with AKI patients with an initial raised creatinine level that later decreased (Table 6). Similarly, outcome was worse in AKI III patients who gradually progressed from AKI I or AKI II to AKI III compared with patients with AKI III without prior decline. 
Table 2

Characteristics and outcome depending on degree of renal function.

\begin{tabular}{|c|c|c|c|c|c|c|c|}
\hline & $\begin{array}{c}\text { No AKI } \\
n=14,405 \\
(65.6 \%)\end{array}$ & $\begin{array}{c}\text { AKI 1 } \\
n=4259 \\
(19.1 \%)\end{array}$ & $\begin{array}{c}\text { AKI II } \\
n=857 \\
(3.8 \%)\end{array}$ & $\begin{array}{c}\text { AKI III } \\
n=2782 \\
(12.5 \%)\end{array}$ & $\begin{array}{c}\text { AKI } \\
(I+I I+I I I) \\
n=7898 \\
(35.4 \%)\end{array}$ & $\begin{array}{c}p \\
\text { AKI } \\
\text { vs no AKI }\end{array}$ & $\begin{array}{c}\text { p } \\
\text { AKI III } \\
\text { vs } \\
\text { AKI I }\end{array}$ \\
\hline \multicolumn{8}{|l|}{ Age } \\
\hline Mean (SD) & $60.5(16.56)$ & $62.1(15.93)$ & $60.4(16.55)$ & $61.1(15.66)$ & $61.5(15.91)$ & $<0.0001$ & 0.089 \\
\hline Range & 16 to 99 & 16 to 95 & 16 to 92 & 16 to 90 & 16 to 95 & & \\
\hline \multicolumn{8}{|c|}{ APACHE II score at admission to ICU } \\
\hline Median & 13 & 16 & 17 & 21 & 18 & $<0.0001$ & $<0.0001$ \\
\hline Range & 0 to 49 & 0 to 44 & 3 to 39 & 1 to 52 & 0 to 52 & & \\
\hline \multicolumn{8}{|c|}{ SOFA score on admission to ICU } \\
\hline Median & 5 & 7 & 7 & 9 & 7 & $<0.0001$ & $<0.0001$ \\
\hline Range & 0 to 21 & 0 to 18 & 2 to 19 & 0 to 22 & 0 to 22 & & \\
\hline \multicolumn{8}{|c|}{ Number of associated failed organs at admission to ICU* } \\
\hline Median & 0 & 1 & 1 & 1 & 1 & $<0.0001$ & $<0.0001$ \\
\hline Range & 0 to 6 & 0 to 5 & 0 to 5 & 0 to 6 & 0 to 6 & & \\
\hline \multicolumn{8}{|c|}{ Maximum number of associated failed organ systems* } \\
\hline Median & 1 & 1 & 2 & 2 & 2 & $<0.0001$ & $<0.0001$ \\
\hline Range & 0 to 6 & 0 to 5 & 0 to 6 & 0 to 6 & 0 to 6 & & \\
\hline \multicolumn{8}{|c|}{ Mechanical ventilation } \\
\hline Number of patients & $8379(58.2 \%)$ & $\begin{array}{c}3441 \\
(80.8 \%)\end{array}$ & $\begin{array}{c}696 \\
(81.2 \%)\end{array}$ & $\begin{array}{c}2416 \\
(86.8 \%)\end{array}$ & $\begin{array}{c}6553 \\
(82.97 \%)\end{array}$ & $<0.0001$ & $<0.0001$ \\
\hline \multicolumn{8}{|l|}{ Outcome } \\
\hline $\begin{array}{l}\text { ICU } \\
\text { mortality }\end{array}$ & $\begin{array}{c}1548 \\
(10.7 \%)\end{array}$ & $\begin{array}{c}856 \\
(20.1 \%)\end{array}$ & $\begin{array}{c}222 \\
(25.9 \%)\end{array}$ & $\begin{array}{c}1379 \\
(49.6 \%)\end{array}$ & $\begin{array}{c}2457 \\
(31.1 \%)\end{array}$ & $<0.0001$ & $<0.0001$ \\
\hline $\begin{array}{l}\text { Hospital } \\
\text { mortality }\end{array}$ & $\begin{array}{c}2438 \\
(16.9 \%)\end{array}$ & $\begin{array}{c}1272 \\
(29.9 \%)\end{array}$ & $\begin{array}{c}307 \\
(35.8 \%)\end{array}$ & $\begin{array}{c}1610 \\
(57.9 \%)\end{array}$ & $\begin{array}{c}3189 \\
(40.4 \%)\end{array}$ & $<0.0001$ & $<0.0001$ \\
\hline \multicolumn{8}{|c|}{ Length of stay in ICU (days): ICU survivors } \\
\hline Median & 2 & 6 & 7 & 9 & 7 & $<0.0001$ & $<0.0001$ \\
\hline Range & (2 to 55$)$ & (3 to 109 ) & (3 to 112 ) & (1 to 270 ) & (1 to 270$)$ & & \\
\hline \multicolumn{8}{|c|}{ Length of stay in ICU (days): ICU non-survivors } \\
\hline Median & 2 & 7 & 7 & 8 & 7 & $<0.0001$ & $<0.0001$ \\
\hline Range & (2 to 64$)$ & (3 to 73 ) & (3 to 54$)$ & (1 to 110$)$ & (1 to 110$)$ & & \\
\hline \multicolumn{8}{|c|}{ Timing of $\mathrm{AKI}$ in ICU } \\
\hline First 48 hours & - & $3529(82.9 \%)$ & $558(65.1 \%)$ & $2075(74.6 \%)$ & $6162(78.0 \%)$ & & \\
\hline Day 3 to 5 & - & $424(9.96 \%)$ & $120(14.0 \%)$ & 332 (11.9\%) & $876(11.1 \%)$ & & \\
\hline Day 6 to 9 & - & $193(4.5 \%)$ & $68(7.9 \%)$ & $207(7.4 \%)$ & 468 (5.9\%) & & \\
\hline Day $10-14$ & - & $\begin{array}{c}73 \\
(1.7 \%)\end{array}$ & $\begin{array}{c}49 \\
(5.7 \%)\end{array}$ & $\begin{array}{c}99 \\
(3.6 \%)\end{array}$ & $\begin{array}{c}221 \\
(2.8 \%)\end{array}$ & & \\
\hline Day $15-19$ & - & $\begin{array}{c}20 \\
(0.5 \%)\end{array}$ & $\begin{array}{c}20 \\
(2.3 \%)\end{array}$ & $\begin{array}{c}31 \\
(1.1 \%)\end{array}$ & $\begin{array}{c}71 \\
(0.9 \%)\end{array}$ & & \\
\hline$>19^{\text {th }}$ day & - & $\begin{array}{c}20 \\
(0.5 \%)\end{array}$ & $\begin{array}{c}42 \\
(4.9 \%)\end{array}$ & $\begin{array}{c}38 \\
(1.4 \%)\end{array}$ & $\begin{array}{c}100 \\
(1.3 \%)\end{array}$ & & \\
\hline
\end{tabular}

* excluding acute kidney injury $\mathrm{AKI}=$ acute kidney injury; APACHE = Acute Physiology and Chronic Health Evaluation; ICU = intensive care unit; SD = standard deviation; SOFA score $=$ Sequential Organ Failure Assessment score. 
Figure 1

ICU mortality [\%]

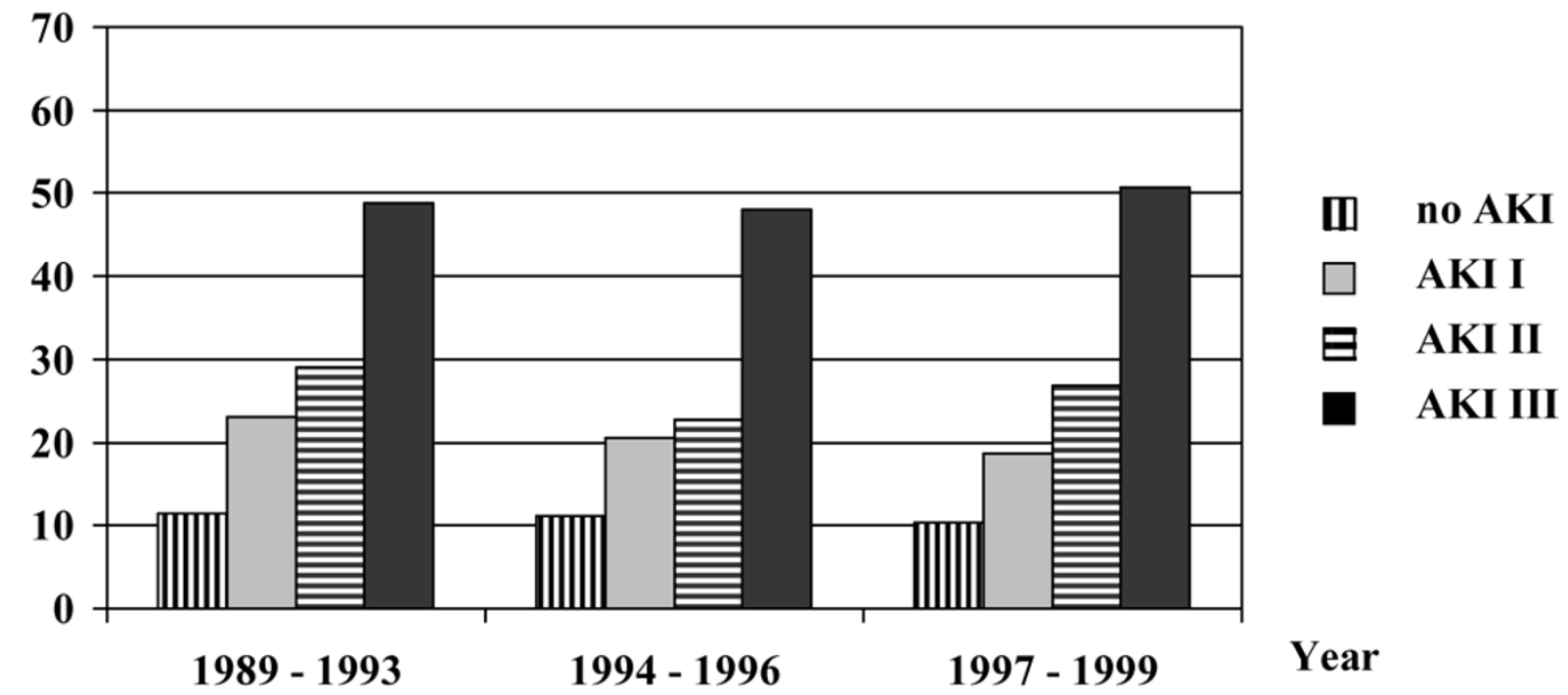

Outcome of $\mathrm{AKI}$ over time. $\mathrm{AKI}=$ acute kidney injury; ICU = intensive care unit.

Figure 2

\section{ICU mortality [\%]}

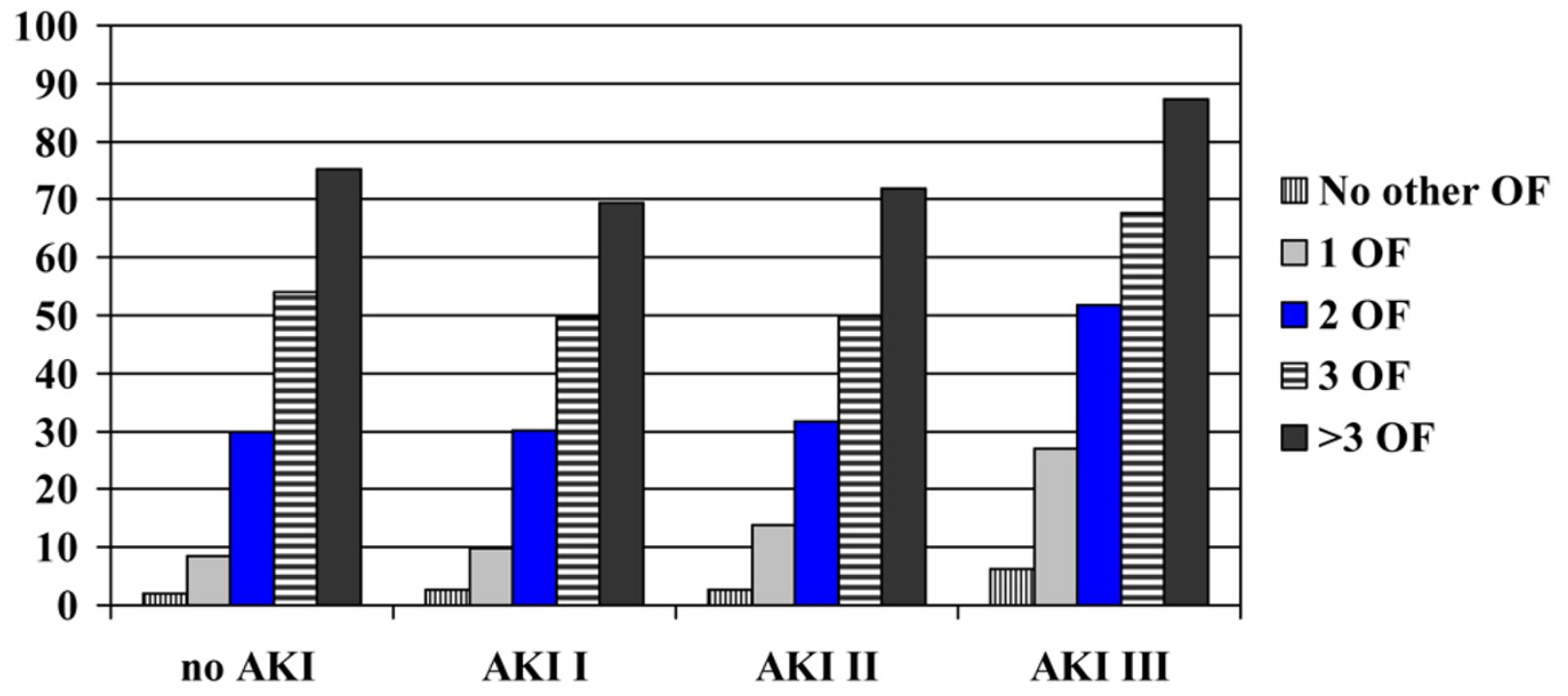

Impact of associated maximum organ failure. $\mathrm{AKI}=$ acute kidney injury; ICU = intensive care unit; $\mathrm{OF}=$ number of maximum associated failed organ systems. 
Table 3

Differences between AKI III on RRT and AKI III without RRT.

\begin{tabular}{|c|c|c|c|}
\hline Factor & $\begin{array}{c}\text { AKI III } \\
\text { on RRT } \\
(n=1847)\end{array}$ & $\begin{array}{c}\text { AKI III } \\
\text { without RRT } \\
(n=935)\end{array}$ & p \\
\hline Male gender & $1242(67.2 \%)$ & $660(70.6 \%)$ & 0.08 \\
\hline \multicolumn{4}{|l|}{ Age } \\
\hline Mean (SD) & $60.09(15.68)$ & $63.14(15.42)$ & 0.28 \\
\hline \multicolumn{4}{|l|}{ APACHE II on admission to ICU } \\
\hline Median (range) & 22 (1 to 52$)$ & 19 (2 to 46$)$ & $<0.0001$ \\
\hline Mean (SD) & $22.92(7.80)$ & $19.84(6.63)$ & \\
\hline \multicolumn{4}{|l|}{ SOFA score on admission to ICU } \\
\hline Median (range) & 10 (0 to 22$)$ & 7 (0 to 17 ) & 0.0063 \\
\hline Mean (SD) & $10.23(3.18)$ & $7.61(2.96)$ & \\
\hline \multicolumn{4}{|l|}{ Organ failure on admission to ICU* } \\
\hline Median (range) & 2 (0 to 6$)$ & $1(0$ to 4$)$ & $<0.0001$ \\
\hline Mean (SD) & $1.72(1.20)$ & $1.11(0.95)$ & \\
\hline \multicolumn{4}{|l|}{ Maximum organ failure during ICU* } \\
\hline Median (range) & $2(0$ to 6$)$ & 2 (0 to 6$)$ & $<0.0001$ \\
\hline Mean (SD) & $2.27(1.17)$ & $1.67(0.97)$ & \\
\hline Mechanical ventilation & $1687(91.3 \%)$ & $729(77.97 \%)$ & $<0.0001$ \\
\hline Pre-existing chronic illness & $469(25.4 \%)$ & $238(25.5 \%)$ & 0.97 \\
\hline Haemoglobin $\leq 9 \mathrm{~g} / \mathrm{dl}$ on admission to the ICU & $496(26.9 \%)$ & $193(20.6 \%)$ & 0.0004 \\
\hline Cardiac surgery & $236(12.8 \%)$ & $95(10.2 \%)$ & 0.051 \\
\hline \multicolumn{4}{|l|}{ Mortality } \\
\hline ICU mortality & $999(54.1 \%)$ & $380(40.6 \%)$ & $<0.0001$ \\
\hline Hospital mortality & $1138(61.6 \%)$ & $472(50.5 \%)$ & $<0.0001$ \\
\hline
\end{tabular}

* excluding acute kidney injury

$\mathrm{AKI}=$ acute kidney injury; APACHE = Acute Physiology and Chronic Health Evaluation; ICU = intensive care unit; RRT = renal replacement therapy; SD = standard deviation; SOFA score = Sequential Organ Failure Assessment score.

Impact of RRT as a criterion for AKI III

The definition of AKI III includes 'treatment with RRT', which is a subjective criterion. We examined how many patients with AKI III would have been categorised differently if RRT had not been used as a criterion. Of a total of 2782 AKI III patients, 1847 had RRT of whom only 573 patients fulfilled the creatinine criteria for AKI III. Of the remaining group, 691 patients were oliguric with a urine output $<400 \mathrm{ml} /$ day and would have (probably) fulfilled the urine criteria for AKI III. The remaining 583 patients had RRT without a $300 \%$ change in creatinine or a creatinine $\geq 354 \mu \mathrm{mol} / \mathrm{L}$ (as per AKI III criteria) or without being oliguric. Their ICU mortality was $43.4 \%$. If RRT had not been included as a criterion for AKI III, these patients would have been classified as having AKI II, AKI I or even 'no AKI' which would have changed the overall mortality in these groups.

\section{Discussion}

To date, all proposed classifications for AKI (RIFLE criteria [2] and differentiation between acute renal injury, acute renal failure and acute renal failure syndrome [10]) have demonstrated that the risk of death is higher in patients with a worse degree of $A K I$, independent of how $A K I$ is defined [4,11]. Our data show that the same applied to the AKI classification: ICU mortality was higher in patients with different degrees of AKI compared with patients without AKI. However, in contrast to the RIFLE classification, only AKI III was independently associated with ICU mortality.

The validity of any classification system for AKI depends on whether it clearly differentiates between normal renal function and $\mathrm{AKI}$, as well as between different grades of severity. The exact cut-off criteria need to be objective and prognostic but 
Characteristics of ICU survivors and non-survivors (univariate analysis).

\begin{tabular}{|c|c|c|c|c|c|c|}
\hline \multirow[t]{2}{*}{ Characteristics } & \multicolumn{2}{|l|}{$\begin{array}{c}\text { ICU } \\
\text { Survivors } \\
(n=18,298)\end{array}$} & \multicolumn{2}{|l|}{$\begin{array}{c}\text { ICU } \\
\substack{\text { Non-survivors } \\
(n=4005)}\end{array}$} & \multirow[t]{2}{*}{$\begin{array}{l}\text { Odds ratio } \\
(95 \% \mathrm{Cl})\end{array}$} & \multirow[t]{2}{*}{$\mathbf{p}$} \\
\hline & $\mathbf{n}$ & $\%$ & $\mathbf{N}$ & $\%$ & & \\
\hline Male gender & 11,265 & 61.6 & 2441 & 60.9 & 0.97 (0.91 to 1.05$)$ & 0.48 \\
\hline Mean age in years $(95 \% \mathrm{Cl})$ & $60.3(60.1$ to 60.6$)$ & & 63.5 (63.0 to 63.95$)$ & & & $<0.0001$ \\
\hline $\begin{array}{l}\text { Median APACHE II score at admission to ICU } \\
\text { (range) }\end{array}$ & $13(0$ to 49$)$ & & 21 (0 to 52$)$ & & & $<0.0001$ \\
\hline $\begin{array}{l}\text { Median SOFA score on admission to ICU } \\
\text { (range) }\end{array}$ & 5 (0 to 20$)$ & & 8 (0 to 22$)$ & & & $<0.0001$ \\
\hline \multicolumn{7}{|l|}{ Degree of maximum renal dysfunction } \\
\hline No AKI & 12,857 & 70.3 & 1,548 & 38.7 & 0.55 (0.53 to 0.57$)$ & $<0.0001$ \\
\hline AKII & 3403 & 18.6 & 856 & 21.4 & 1.15 (1.08 to 1.23$)$ & $<0.0001$ \\
\hline AKI II & 635 & 3.5 & 222 & 5.5 & 1.60 (1.38 to 1.85$)$ & $<0.0001$ \\
\hline AKI III & 1403 & 7.7 & 1379 & 34.4 & $4.49(4.20$ to 4.80$)$ & $<0.0001$ \\
\hline \multicolumn{7}{|l|}{ Type of admission } \\
\hline Non-surgical & 9236 & 50.5 & 2873 & 71.7 & 2.49 (2.31 to 2.68$)$ & $<0.0001$ \\
\hline Elective surgery & 6328 & 34.6 & 477 & 11.9 & $0.26(0.23$ to 0.28$)$ & $<0.0001$ \\
\hline Emergency surgery & 2734 & 14.9 & 655 & 16.4 & $1.11(1.01$ to 1.22$)$ & 0.026 \\
\hline \multicolumn{7}{|l|}{ Source of admission } \\
\hline Operating room & 8561 & 46.8 & 1072 & 26.8 & & \\
\hline Emergency room & 3413 & 18.7 & 750 & 18.7 & & \\
\hline Ward (including HDU) & 3845 & 21.0 & 1574 & 39.3 & & \\
\hline Hospital transfers & 1894 & 10.4 & 531 & 13.3 & & \\
\hline Recovery room & 543 & 3.0 & 62 & 1.5 & & \\
\hline Other & 42 & 0.2 & 16 & 0.4 & & \\
\hline \multicolumn{7}{|l|}{ Chronic end-stage diseases } \\
\hline Present & 3225 & 17.6 & 1,148 & 28.7 & 1.88 (1.74 to 2.03$)$ & $<0.0001$ \\
\hline \multicolumn{7}{|l|}{ Haemoglobin on admission to ICU } \\
\hline Haemoglobin $\geq 9 \mathrm{~g} / \mathrm{dl}$ & 15,846 & 86.6 & 3238 & 80.8 & & \\
\hline Haemoglobin $<9 \mathrm{~g} / \mathrm{dl}$ & 2452 & 13.4 & 767 & 19.2 & $1.53(1.40$ to 1.67$)$ & $<0.0001$ \\
\hline \multicolumn{7}{|l|}{ Cardiac surgery * } \\
\hline Admission post cardiac surgery & 2507 & 13.7 & 244 & 6.1 & $0.41(0.36$ to 0.47$)$ & $<0.0001$ \\
\hline \multicolumn{7}{|l|}{ Mechanical ventilation } \\
\hline Ventilated & 11,274 & 61.6 & 3658 & 91.3 & 6.57 (5.86 to 7.36$)$ & $<0.0001$ \\
\hline \multicolumn{7}{|l|}{ Renal replacement therapy } \\
\hline RRT for AKI & 848 & 4.6 & 999 & 24.9 & $5.38(4.94$ to 5.86$)$ & $<0.0001$ \\
\hline \multicolumn{7}{|c|}{ Number of failed organs on day of admission to ICU } \\
\hline 0 failed organ & 9210 & 50.3 & 704 & 17.6 & 0.21 (0.19 to 0.23$)$ & $<0.0001$ \\
\hline 1 failed organ & 6561 & 35.9 & 1455 & 36.3 & $1.02(0.95$ to 1.10$)$ & 0.58 \\
\hline 2 failed organs & 2068 & 11.3 & 1164 & 29.1 & 3.22 (2.96 to 3.49$)$ & $<0.0001$ \\
\hline$\geq 3$ failed organs & 459 & 2.5 & 682 & 17.0 & 7.98 (7.05 to 9.03$)$ & $<0.0001$ \\
\hline \multicolumn{7}{|c|}{ Maximum number of associated organ failures during entire ICU stay (including AKI) } \\
\hline 0 failed organ & 5653 & 30.9 & 96 & 2.4 & 0.05 (0.04 to 0.07$)$ & $<0.0001$ \\
\hline 1 failed organ & 6110 & 33.4 & 459 & 11.5 & $0.26(0.23$ to 0.29$)$ & $<0.0001$ \\
\hline 2 failed organs & 4053 & 22.1 & 993 & 24.8 & $1.16(1.07$ to 1.26$)$ & 0.0003 \\
\hline 3 failed organs & 1933 & 10.6 & 1350 & 33.7 & 4.31 (3.97 to 4.67 ) & $<0.0001$ \\
\hline$>3$ failed organs & 549 & 3.0 & 1107 & 27.6 & $12.35(11.07$ to 13.78$)$ & $<0.0001$ \\
\hline
\end{tabular}

* coronary artery bypass surgery and/or valve surgery.

$\mathrm{AKI}=$ acute kidney injury; $\mathrm{APACHE}=$ Acute Physiology and Chronic Health Evaluation; $\mathrm{Cl}=$ confidence interval; $\mathrm{HDU}=$ high dependency unit; $\mathrm{ICU}=$ intensive care unit; RRT = renal replacement therapy; SOFA score = Sequential Organ Failure Assessment score. 
Critical Care Vol 12 No 6 Ostermann et al.

Table 5

\begin{tabular}{|c|c|c|c|c|}
\hline Variables & B & $\mathbf{p}$ & OR & $95 \% \mathrm{Cl}$ \\
\hline Admission post cardiac surgery & -0.567 & 0.000 & 0.567 & 0.47 to 0.69 \\
\hline RRT for AKI & -0.202 & 0.039 & 0.817 & 0.674 to 0.99 \\
\hline Age & 0.024 & 0.000 & 1.025 & 1.02 to 1.03 \\
\hline SOFA score on admission to ICU & 0.104 & 0.000 & 1.109 & 1.09 to 1.13 \\
\hline Pre-existing chronic diseases & 0.499 & 0.000 & 1.647 & 1.49 to 1.82 \\
\hline \multicolumn{5}{|l|}{ Renal function } \\
\hline \multicolumn{5}{|l|}{ No AKI } \\
\hline AKI I & -0.024 & 0.000 & 0.82 & 0.73 to 0.91 \\
\hline AKI II & 0.051 & 0.59 & 1.05 & 0.87 to 1.27 \\
\hline AKI III & 0.820 & 0.000 & 2.27 & 1.92 to 2.69 \\
\hline Admission after emergency surgery & 0.846 & 0.000 & 2.329 & 1.997 to 2.72 \\
\hline Maximum number of failed organ systems in ICU & 1.028 & 0.000 & 2.795 & 2.66 to 2.94 \\
\hline Ventilation & 1.040 & 0.000 & 2.828 & 2.48 to 3.23 \\
\hline Non-surgical admission & 1.273 & 0.000 & 3.572 & 3.12 to 4.09 \\
\hline Constant & -5.589 & 0.000 & 0.004 & \\
\hline
\end{tabular}

$\mathrm{AKI}=$ acute kidney injury; $\mathrm{Cl}=$ confidence interval; $\mathrm{ICU}=$ intensive care unit; $\mathrm{OR}=$ odds ratio; RRT = renal replacement therapy; SOFA score = Sequential Organ Failure Assessment score.

should also be easy to ascertain. The RIFLE classification meets some of these standards but not all $[12,13]$. The latest $\mathrm{AKI}$ staging system represents an improvement: it has a lower cut-off for AKI (i.e. rise in serum creatinine by $\geq 0.3 \mathrm{mg} / \mathrm{dl}$ or $26.4 \mu \mathrm{mol} / \mathrm{L}$ ) based on data by Chertow and colleagues [14] and no longer uses 'estimated glomerular filtration rate' as a criterion but only serum creatinine and urine output. Other important changes from the RIFLE classification are the inclusion of a 48-hour window for the diagnosis of AKI and the decision to classify patients on RRT automatically as having AKI III.

Table 6

\begin{tabular}{|c|c|c|c|}
\hline AKI progression & Number of patients & ICU mortality & $\mathbf{p}$ \\
\hline \multicolumn{4}{|l|}{ AKI I $(n=4259)$} \\
\hline with rising creatinine values & $1995(46.8 \%)$ & $522(26.2 \%)$ & $<0.0001$ \\
\hline with falling creatinine values & $2264(53.2 \%)$ & $334(14.8 \%)$ & \\
\hline \multicolumn{4}{|l|}{ AKI II $(n=857)$} \\
\hline with rising creatinine values & $439(51.2 \%)$ & $157(35.8 \%)$ & $<0.0001$ \\
\hline with falling creatinine values & $418(48.8 \%)$ & $65(15.6 \%)$ & \\
\hline \multicolumn{4}{|l|}{ AKI III $(n=2782)$} \\
\hline with rising creatinine values & $639(23 \%)$ & $318(49.8 \%)$ & $<0.0001$ \\
\hline with falling creatinine values & $296(10.6 \%)$ & $62(20.9 \%)$ & \\
\hline AKI III based on RRT criteria & $1847(66.4 \%)$ & $999(54.1 \%)$ & \\
\hline AKI I/AKI II progressing to AKI III & $1664(59.8 \%)$ & $796(47.8 \%)$ & $p=0.029$ \\
\hline AKI III without prior AKI I/AKI II & $1118(40.2 \%)$ & $583(46.2 \%)$ & \\
\hline
\end{tabular}

$\mathrm{AKI}=$ acute kidney injury; ICU = intensive care unit; RRT = renal replacement therapy. 
Despite its correlation with outcome, this new classification is still not perfect. Firstly, the criteria for AKI III are a mixture of creatinine values, urine results and a therapeutic intervention (i.e. RRT). Due to the lack of universal guidelines for RRT (when to start, which type of RRT to use in what dose and when to stop), RRT is a completely subjective criterion, dependent on individual decision making. In our study, 31.6\% of all patients on RRT had a rise in creatinine of less than $300 \%$ and a urine output of more than $400 \mathrm{ml} / 24$ hours when RRT was started. These patients were only classified as having AKI III because of RRT. The clinical but subjective decision for or against RRT can automatically change the AKI category. Although patients with AKI III on RRT had a worse outcome than AKI III patients not treated with RRT (Table 3), in a multivariate analysis, RRT was independently associated with a reduced risk of mortality in the ICU. Without clear consensus on the practice of RRT, these limitations of the proposed AKI classification are difficult to overcome unless a marker of renal function can be identified that is not affected by any therapeutic interventions.

A time frame is clearly important for the diagnosis of AKI. The AKI network chose a 48-hour window which will ensure that identified cases are definitely 'acute'. However, a narrow window like this may miss patients with progressive renal dysfunction in whom the creatinine level rises steadily but never by more than $0.3 \mathrm{mg} / \mathrm{dl}(26.4 \mu \mathrm{mol} / \mathrm{L})$ or $150 \%$ in 48 hours and never beyond $354 \mu \mathrm{mol} / \mathrm{L}$, the criteria for AKI III. In our analysis, 2014 patients classified as having no AKI, had serum creatinine levels of more than $140 \mathrm{~mol} / \mathrm{L}, 316$ patients even had serum creatinine values of more than $270 \mu \mathrm{mol} / \mathrm{L}$. Although it is possible that they may have had a degree of pre-existing chronic kidney disease, it is also possible that they had AKI without the necessary changes in serum creatinine within the required time period. A one-week time frame was previously suggested by the ADQI group in the original RIFLE criteria. Using the AKI classification with a seven-day instead of a 48hour time frame, we found a higher incidence of AKI $(39.5 \%$ instead of 34.4\%; AKI I 19.3\%, AKI II 6.7\% and AKI III 13.5\%). ICU mortality would have altered only slightly (AKI I 21.0\%, AKI II 24.9\%, AKI III 49.0\%).

Our results confirm that $\mathrm{AKI}$ in ICU patients is not only a very common problem (34.4\%) but also correlates with significant mortality. AKI III was associated with almost the same risk of death in the ICU as having emergency surgery. Although loss of renal function results in metabolic and physiological derangements and is often associated with other chronic and acute comorbidities, our analysis shows that the worse prognosis of AKI III was independent of other organ failures or being ventilated. Clermont and colleagues also previously suggested that the increased mortality of patients with AKI was not simply due to loss of renal function per se and that other, so far unknown, factors were responsible [15]. They compared $254 \mathrm{ICU}$ patients with $\mathrm{AKI}$ as defined by graded changes in serum creatinine with 57 ICU patients with dialysisdependent ESRF. They showed that patients treated with either continuous venovenous haemodialysis or intermittent haemodialysis for AKI had an ICU mortality rate four-times higher than ESRF patients. At first glance, our data would confirm this: ICU mortality among patients with AKI III treated with RRT was significantly higher than that of the excluded 797 patients with ESRF (53.8\% versus $20.8 \%$; $p<0.0001$ ). However, patients with AKI III were generally sicker as evidenced by more associated organ failure and a higher proportion of patients on mechanical ventilation (91.3\% versus $60.9 \%$ ), which makes it difficult to compare these two groups.

The reason why only $\mathrm{AKI}$ III, and not $\mathrm{AKI}$ I or AKI II, were independent risk factors for death in the ICU is not clear. A possible explanation may be related to the use of RRT as a criterion: 583 patients received RRT but did not fulfil the creatinine or urine creatinine level for AKI III. Without using RRT as a criterion, these patients would have been classified as having $\mathrm{AKI}$ I or II, which would have altered the outcome in these groups. Further work will be necessary to explain this observation. Hopefully, with ongoing research and work by the AKI network we may be able to gain more insight into the complexities and confounding factors of AKI.

To the best of our knowledge, this is the largest study on the epidemiology of AKI during the entire ICU stay as defined by the newly proposed AKI classification. It is important to consider its strengths and limitations. The retrospective nature is a weakness, especially because we did not have any pre-ICU admission data, including previous creatinine results. However, it would take a long time to validate any new classification system in such a large patient group $(>20,000$ patients in $>$ 20 ICUs) prospectively. Secondly, it is also possible that we may have underestimated the exact incidence of AKI by excluding patients who stayed in the ICU for less than 24 hours. In addition, we only used creatinine levels obtained during the stay in the ICU and may have missed patients with serum creatinine values higher than previous baseline levels but no subsequent change in renal function while in the ICU. Finally, due to the lack of 6- and 12-hour urine results in our database we may have also missed patients who would have fulfilled the AKI criteria on urine results only. Therefore, the true incidence of $\mathrm{AKI}$ in the ICU may have been higher than 34.4\%. It is also worth acknowledging that our conclusions are based on data from a 10-year period before 2000. Although we didn't find any significant changes in outcome between 1989 and 1999 , it is possible that they have occurred since.

A major strength of this work is its size and comprehensive analysis. The results are based on a large cohort of more than 20,000 patients who were heterogeneous in terms of baseline demographics, acute medical problems and comorbidities, which makes them representative of a wide ICU population. Our conclusions are strengthened by the fact that we control- 
led for several important risk factors as part of the validation process.

\section{Conclusion}

The proposed classification for AKI correlated with ICU and hospital outcome but only AKI III was an independent risk factor for ICU mortality. The introduction of a 48-hour time frame for the diagnosis of AKI may miss patients with a slow but progressive decline in renal function. RRT as a criterion for AKI III is not objective and may have had a confounding effect on the predictive power of the classification system as a whole.

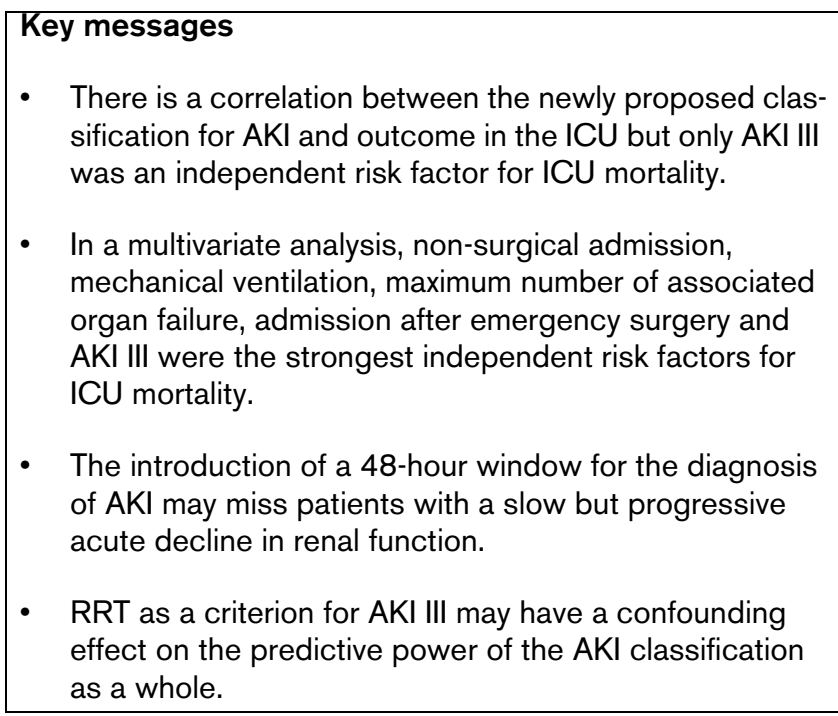

\section{Competing interests}

The authors declare that they have no competing interests.

\section{Authors' contributions}

$\mathrm{RC}$ is in charge of the Riyadh Intensive Care Program database. Both authors extracted the data from the database and performed the analyses. MO wrote the draft and RC provided critiques. Both authors approved the final manuscript.

\section{Additional files}

The following Additional files are available online:

\section{Additional file 1}

a word file containing a description of the computer algorithm used to identify patients with AKI. See http://www.biomedcentral.com/content/ supplementary/cc7123-S1.doc

\section{Additional file 2}

a word file containing two tables that illustrate in detail how the computer algorithm works.

See http://www.biomedcentral.com/content/ supplementary/cc7123-S2.doc

\section{Acknowledgements}

We wish to thank the Riyadh ICU Program Users Group for access to the data used in this study.

\section{References}

1. Mehta RL, Chertow GM: Acute renal failure definitions and classification: time for change? J Am Soc Nephrol 2003, 14:2178-2187.

2. Bellomo R, Ronco C, Kellum JA, Mehta RL, Palevsky P, the ADQI workgroup: Acute renal failure - definition, outcome measures, animal models, fluid therapy and information technology needs: the Second International Consensus Conference of the Acute Dialysis Quality Initiative (ADQI) Group. Crit Care 2004 8:R204-R212.

3. Mehta RL, Kellum JA, Shah SV, Molitoris BA, Ronco C, Warnock DG, Levin A: Acute Kidney Injury Network (AKIN): report of an initiative to improve outcomes in acute kidney injury. Crit Care 2007, 11:R31.

4. Ricci Z, Cruz D, Ronco C: The RIFLE criteria and mortality in acute kidney injury: A systematic review. Kidney Int 2008, 73:538-546.

5. Barrantes F, Tian J, Vazquez R, Amoatent-Adjepong Y, Manthous CA: Acute kidney injury criteria predict outcomes of critically ill patients. Crit Care Med 2008, 36:1397-1403.

6. Bagshaw SM, George C, Bellomo R, ANZICS Database Management Committee: A comparison of the RIFLE and AKIN criteria for acute kidney injury in critically ill patients. Nephrol Dial Transplant 2008, 23:1569-1574.

7. Vincent JL, de Mendonca A, Cantraine F, Moreno R, Takala J, Suter PM, Sprung CL, Colardyn F, Blecher S: Use of the SOFA score to assess the incidence of organ dysfunction/failure in intensive care units: results of a multicenter, prospective study. Crit Care Med 1998, 26:1793-1800.

8. Knaus WA, Draper EA, Wagner DP, Zimmermann JE: Prognosis in acute organ-system failure. Ann Surg 1985, 202:685-693.

9. Chang RWS, Jacobs S, Lee B: Gastrointestinal dysfunction among intensive care unit patients. Crit Care Med 1987, 15:909-914.

10. Bellomo R, Kellum J, Ronco C: Acute renal failure: time for consensus. Intensive Care Med 2001, 27:1685-1688.

11. Ostermann $M$, Chang RW: Acute kidney injury in the intensive care unit according to RIFLE. Crit Care Med 2007, 35:1837-1843.

12. Ostermann ME, Chang RW: Prognosis of acute renal failure: an evaluation of proposed consensus criteria. Intensive Care Medicine 2005, 31:250-256.

13. Ostermann M, Chang R: The RIFLE criteria: Are the foundations robust? Crit Care Med 2007, 35:2669-2670.

14. Chertow GM, Burdick E, Honour M, Bonventre JV, Bates DW: Acute kidney injury, mortality, length of stay, and costs in hospitalized patients. J Am Soc Nephrol 2005, 16:3365-3370.

15. Clermont G, Acker CG, Angus DC, Sirio CA, Pinsky MR, Johnson JP: Renal failure in the ICU: comparison of the impact of acute renal failure and end-stage renal disease on ICU outcome. Kidney Int 2002, 62:986-996. 